\title{
Knowledge gaps regarding frugivorous ecological networks between birds and plants in Brazil
}

\author{
Cristian Daniel Veliz Baldiviezo ${ }^{1,2}$; Marcela Fortes de Oliveira Passos ${ }^{1,3}$ \& Cristiano Schetini de Azevedo ${ }^{1,4}$ \\ 1 Universidade Federal de Ouro Preto (UFOP), Instituto de Ciências Exatas e Biológicas (ICEB), Departamento de Biodiversidade, \\ Evolução e Meio Ambiente (DEBI0), Laboratório de Zoologia dos Vertebrados. Ouro Preto, MG, Brasil. \\ ${ }^{2}$ ORCID: http://orcid.org/0000-0001-5883-097X. E-mail: cristian_v_b_y@hotmail.com \\ 3 ORCID: http://orcid.org/0000-0002-0992-5515. E-mail: marcelabiol@hotmail.com \\ ${ }^{4}$ ORCID: http://orcid.org/0000-0003-0256-9017. E-mail: cristianoroxette@yahoo.com (corresponding author)
}

\begin{abstract}
Vegetation stability, resilience and regeneration can be achieved by various ecological processes, the most important of which is seed dispersion. Among animal groups, birds have the largest number of frugivorous species in the Neotropics. The aim of this study was to conduct a bibliometric analysis to detect general patterns and discover knowledge gaps in order to identify future directions for research into bird frugivory in Brazil. A gap analysis was carried out by obtaining 77 articles published online and evaluating their data in different ways. The results revealed that research on bird frugivory in Brazil was published in 33 scientific journals and financed by 18 national and international funding agencies. The number of publications increased over time, with the majority of them reporting research carried out in biomes of Central-West and South regions of Brazil. The most important bird species in frugivorous interactions in the most studied biomes were identified, including some non-native species. Our results corroborate several other studies, which together demonstrate a lack research on frugivorous interactions in the North and Northeast of Brazil, where there are very important biomes for conservation, such as the Amazon and Caatinga, for which knowledge of seed dispersal processes is needed.
\end{abstract}

Key-Words. Frugivory; Seed dispersion; Bird-plant interactions; Biomes; Bibliometric analysis.

\section{INTRODUCTION}

Vegetation stability, resilience and regeneration, can be achieved by various ecological processes, the most important of which is seed dispersion (Levine \& Murrell, 2003; Angulo, 2011). Seed dispersion is the procedure of transporting the spreads away from the mother plant for the development of new plant individuals, that is very important to the function, structure and dynamics of forest ecosystems since it helps maintain plant populations and several other benefits (such as soil fertility, fruit production, presence of fauna, pollination, etc.). Consequently, such events provide many benefits to the entire community, including humans, such as food, clean water and carbon sequestration, among others (Jordano et al., 2006).

Seed dispersion can occur by different ways such as wind, water or animals (zoochory), and within the latter, the frugivory is the act of eating fruits, with their seeds being defecated or regurgitated far from the mother plant (Howe \& Smallwood, 1982). According with Ferreira \& De
Marco (2004), birds are the animal group with the largest number of frugivorous species in the Neotropics, and they play a fundamental role in the establishment of native vegetation in degraded areas by dispersing seeds and creating nucleation areas that accelerate the regeneration processes, contributing to the conservation of such areas. Thus, diminution in the diversity of bird species also diminishes the diversity of dispersed plants (Howe \& Smallwood, 1982), slowing down the regeneration and the conservation of the areas.

Numerous works have described the process of seed dispersal by birds recording the species that are part of the interaction in different environments of Brazil, like Ferreira \& De Marco (2004) in the Atlantic Forest, Allenspach \& Dias (2012) in Brazilian savanna (Cerrado), Ragusa-Netto (2006) in the Pantanal, Cardoso da Silva et al. (1996) in Amazonian rainforest and Gomes et al. (2017) in the Caatinga. There are many different studies about bird frugivory in Brazil in the literature; here, we provide only one example for each Brazilian biome. On the other hand, studies on bird fru- 
givory and seed dispersion began in the 1970's, but it was not until the 1990's that interest and recognition of the importance of interactions between different plants and animals arose (Jordano et al., 2006). Furthermore, these studies were largely conducted in fragmented and anthropized areas (Angulo, 2011). This could influence the results about the relation between birds and plants, since in anthropized areas we can normally find a homogenized bird community, with highly tolerated human-disturbance species and almost no human-disturbance intolerant species, who tend to disappear from these areas (Cardoso da Silva et al., 1996) so their relation to the plant species can be hardly ever recorded.

The relations between frugivorous birds and fruits of zoochoric plants create an interaction network that represent the possibilities of seed dispersion in the ecosystem where they live, and network analytical tools have allowed the operationalization of ecological concepts, such as specialization, functional groups and keystone species (Mello et al., 2015). Some of the metrics permit to select the most important species in the network, helping in more effective conservation measures for the habitat. The degree of connection (the number of times in which an interaction between two species is recorded), the degree of centrality (the number of species in which each member of the network has interaction records), the degree of centrality by proximity or closeness degree (this indicates the species nearest to all other species within the network) and the degree of intermediate centrality or betweenness degree (this indicates the main intermediary species between two others in the networks), and the modularity (indicates the most connected species within the network) are examples of network metrics important to identify keystone species in the habitat. There are other network metrics, such as specialization (the number of partners or links in the network), but they were not chosen because they are considered very complex for a bibliographic analysis.

According to Angulo (2011), studies of frugivory interactions and seed dispersion by birds in South America have been scattered throughout tropical and subtropical regions. For that reason, local evaluations in each country will be needed, since the characteristics of ecosystem services are likely to vary across geographical and temporal scales. Gap analysis holds great potential for such evaluations, because it is an extensive bibliometric assessment of a specific topic looking for information gaps and can serve as a guide for future research (Azevedo et al., 2006). Thus, the aim of this study was to conduct a bibliometric analysis to detect general patterns and networks, and to identify geographical or temporal knowledge gaps, to direct future research into bird frugivory in Brazil. We expected an increase in the literature about the theme over the years, an unequal distribution of the studies through Brazilian biomes, since most of the researchers and institutions are placed in the central-southern areas of the country, where the Atlantic Forest and the Cerrado are present, and that some plant and bird species will have many connections in the networks, acting as key stones in the biomes.

\section{MATERIAL AND METHODS}

A bibliographical search was performed in May 2018 using the scientific databases "Web of Science" and "Google Scholar", with the following keywords: Bird, Seed, Dispersal, Zoochory, Frugivory and Brazil. Combinations of these words, as well as different Boolean connectors (and, in, or, etc.) were employed. A total of 271 scientific publications were found and downloaded to the reference management software "EndNote V5".

Each selected paper was subsequently evaluated, with all documents that were not accessible online and that did not identify or publish their interactions between birds and plants being discarded. This resulted in 77 papers for analysis, and from which the following information was obtained: year of publication, author(s), journal title, university or institution of the first author, study area, Brazilian biome and the interactions between birds that consume fruits of zoochoric plants.

Percentages of each type of information collected were used in the analysis. Although research covered the period from 1945 to 2017, the first papers with the desired information for Brazil were published in 1992, and so the period of publication was divided into 1992 to 2000, 2001 to 2010, and 2011 to 2017. The number of papers per decade was compared using the non-parametric Kruskal-Wallis test with the Dunn's post-hoc test. The chi-square test was use to evaluate whether the number of publications differed among the studied Brazilian biomes. Data gathered about interactions between frugivorous birds and plants in the Atlantic Forest and Cerrado (savannah-like vegetation) biomes were used to construct a complex ecological network; these biomes were chosen because they had the greatest number of publications. For the network analysis, the degree of connection (number of recorded interactions between two species), centrality (the relative importance of species throughout the network) and modularity (the most connected bird and plant groups), were recorded. Network metrics were calculated in the Pajek 5.07 software aiming to identify the keystone species in each Brazilian biome (Mello et al., 2015; Mello et al., 2016).

\section{RESULTS}

The 77 selected articles were published in 33 scientific journals, of which the Brazilian Journal of Biology was the most frequent (14.3\%), followed by Ararajuba (Brazilian Journal of Ornithology) (12.9\%), Biota Neotropica and Biotropica (6.5\% each), with the other journals representing less than $6 \%$ of the publications together (Table 1 ).

Twenty-nine institutions conducted studies about frugivory and bird-plant interactions, with most of the studies being conducted by researchers of the Universidade Federal de São Carlos (13\%), followed by those Universidade Estadual Paulista (10.4\%), and those of Universidade Estadual de Campinas, Universidade de Brasilia and the Universidade Federal de Uberlandia (7.8\% each) (Table 2). These publications were produced 
Table 1. Scientific journals where pulicaitons about frugivory and bird-plant interactions were published from 1992 to 2017.

\begin{tabular}{|c|c|c|}
\hline Scientific Journal & $\mathbf{N}$ & $\%$ \\
\hline Brazilian Journal of Biology & 11 & 14.3 \\
\hline Ararajuba (Brazilian Journal of Ornithology) & 10 & 12.9 \\
\hline Biota Neotropica & 5 & 6.5 \\
\hline Biotropica & 5 & 6.5 \\
\hline Journal of Tropical Ecology & 4 & 5.2 \\
\hline Ornitologia Neotropical & 4 & 5.2 \\
\hline Acta Botânica Brasílica & 3 & 3.9 \\
\hline Atualidades Ornitológicas & 3 & 3.9 \\
\hline Oecologia & 3 & 3.9 \\
\hline Revista Árvore & 3 & 3.9 \\
\hline Flora & 2 & 2.6 \\
\hline Revista Brasileira de Botânica & 2 & 2.6 \\
\hline Zoologia & 2 & 2.6 \\
\hline Acta Amazônica & 1 & 1.3 \\
\hline Agroforestry Systems & 1 & 1.3 \\
\hline Austral Ecology & 1 & 1.3 \\
\hline Biological Conservation & 1 & 1.3 \\
\hline Bioscience Journal & 1 & 1.3 \\
\hline Ciência Florestal & 1 & 1.3 \\
\hline Conservation Biology & 1 & 1.3 \\
\hline Ecotropica & 1 & 1.3 \\
\hline Emu & 1 & 1.3 \\
\hline Floresta e Ambiente & 1 & 1.3 \\
\hline Journal of Ecology & 1 & 1.3 \\
\hline Plant Ecology & 1 & 1.3 \\
\hline Restoration Ecology & 1 & 1.3 \\
\hline Revista de Biologia Tropical & 1 & 1.3 \\
\hline Seed Science Research & 1 & 1.3 \\
\hline Studies of Neotropical Fauna and Environment & 1 & 1.3 \\
\hline The Condor & 1 & 1.3 \\
\hline The Wilson Journal of Ornithology & 1 & 1.3 \\
\hline Tropical Conservation Science & 1 & 1.3 \\
\hline Universidade Federal Rural do Rio de Janeiro & 1 & 1.3 \\
\hline Total & 77 & 100.0 \\
\hline
\end{tabular}

with support from 18 funding agencies, the main one being Conselho Nacional de Desenvolvimento Científico e Tecnológico - CNPq (28.8\%), followed by Coordenação de Aperfeiçoamento de Pessoal de Nível Superior CAPES (20.7\%) and Fundação de Amparo à Pesquisa do Estado de São Paulo - FAPESP (16.2\%); 14.4\% of publications did not specify a funding agency (Table 3 ).

The years with the most publications were 2012 (11.8\%), 2014 (9.2\%), and 2011 and 2017 (7.9\% each) (Fig. 1), with the period of 2011-2017 being the most prolific (53.2\%), followed by 2001-2010 (35\%) and 1992-2000 (11.68\%) $(H=10.05, D F=2, p=0.007)$.

There were publications on bird-plant interactions and frugivory for 14 of the 26 states of Brazil, with São Paulo having the most $(41.6 \%)$, followed by Minas Gerais (16.9\%), Rio de Janeiro, and Rio Grande do Sul (7.8\% each) (Table 4). Among the Brazilian biomes, the Atlantic Forest (53.9\%) and the Cerrado (38.2\%) were the most represented, followed by the Caatinga (5.3\%), the Amazonian Rainforest and the Pantanal (1.3\% each) $\left(X^{2}=16.07, D F=8, p=0.05\right)$ (Fig. 2). Among all of the selected papers, 491 species of plants and 255 species of
Table 2. Institutions that conducted studies on frugivory and bird-plant interactions in Brazil from 1992 to 2017.

\begin{tabular}{lcc}
\hline \multicolumn{1}{c}{ Institutions } & N & $\%$ \\
\hline Universidade Federal de São Carlos & 10 & 13.0 \\
Universidade Estadual Paulista & 8 & 10.4 \\
Universidade de Brasília & 6 & 7.8 \\
Universidade Estadual de Campinas & 6 & 7.8 \\
Universidade Federal de Uberlândia & 6 & 7.8 \\
Universidade Federal de Mato Grosso do Sul & 4 & 5.2 \\
Universidade Federal do Rio de Janeiro & 4 & 5.2 \\
Comité Brasileiro de Registros Ornitológicos & 3 & 3.9 \\
Universidade Federal de Minas Gerais & 3 & 3.9 \\
Universidade Federal de Santa Catarina & 3 & 3.9 \\
Universidade do Estado de Mato Grosso & 2 & 2.6 \\
Universidade Federal de Mato Grosso & 2 & 2.6 \\
Universidade Federal de Viçosa & 2 & 2.6 \\
Universidade Federal do Rio Grande & 2 & 2.6 \\
University of Cambridge & 2 & 2.6 \\
Associação para Gestão Socioambiental do Triângulo Mineiro & 1 & 1.3 \\
Universidade Católica de Salvador & 1 & 1.3 \\
Universidade de Passo Fundo & 1 & 1.3 \\
Universidade de São Paulo & 1.3 \\
Universidade do Estado de Santa Catarina & 1 & 1.3 \\
Universidade do Vale do Rio dos Sinos & 1 & 1.3 \\
Universidade Federal de Alagoas & 1 & 1.3 \\
Universidade Federal de Pernambuco & 1.3 \\
Universidade Federal do Rio Grande do Sul & 1.3 \\
Universidade Federal Rural de Pernambuco & 1 & 1.3 \\
Universidade Federal Rural do Rio de Janeiro & 1.3 \\
Universidade Regional Integrada do Alto Uruguai e das Missões & 1.3 \\
Universitat de Barcelona & 1 & 1 \\
University of Copenhagen & 1 & 1 \\
\hline Total & 1 & 1.3 \\
\hline & 1 & 1 \\
\hline
\end{tabular}

Table 3. Agencies that funded research on frugivory and bird-plant interactions in Brazil from 1992 to 2017.

\begin{tabular}{lcc}
\hline \multicolumn{1}{c}{ Funding Agencies } & N & $\%$ \\
\hline Conselho Nacional de Desenvolvimento Científico e Tecnológico - CNPq & 32 & 28.8 \\
Coordenação de Aperfeiçoamento de Pessoal de Nível Superior - CAPES & 23 & 20.7 \\
Fundação de Amparo à Pesquisa do Estado de São Paulo - FAPESP & 18 & 16.2 \\
Not-specified & 16 & 14.4 \\
Fundação de Amparo à Pesquisa do Estado de Minas Gerais - FAPEMIG & 5 & 4.5 \\
Universidade Federal de Mato Grosso do Sul & 3 & 2.7 \\
Fundação de Amparo à Pesquisa do Mato Grosso - FAPEMAT & 2 & 1.8 \\
Brazilian-German Program Mata Atlântica & 1 & 0.9 \\
Sistema Nacional de Pesquisa em Biodiversidade - SISBIOTA & 1 & 0.9 \\
Fundação de Amparo à Pesquisa do Estado do Rio de Janeiro - FAPERJ & 1 & 0.9 \\
National Geographic Society & 1 & 0.9 \\
Fundação de Amparo à Pesquisa do Estado do Rio Grande do Sul - FAPERGS & 1 & 0.9 \\
Fundação de Amparo à Pesquisa do Estado da Bahia - FAPESB & 1 & 0.9 \\
Fundação Maio Biodiversidade & 1 & 0.9 \\
Idea Wild & 1 & 0.9 \\
Fundação de Amparo à Pesquisa do Estado de Santa Catarina - FAPESC & 1 & 0.9 \\
Universidade de Campinas & 1 & 0.9 \\
Fundação de Amparo à Ciência e Tecnologia do Estado de Pernambuco - FACEPE & 1 & 0.9 \\
Universitat de Barcelona & 1 & 0.9 \\
\hline Total & $\mathbf{1 1 1}$ & $\mathbf{1 0 0 . 0}$ \\
\hline
\end{tabular}




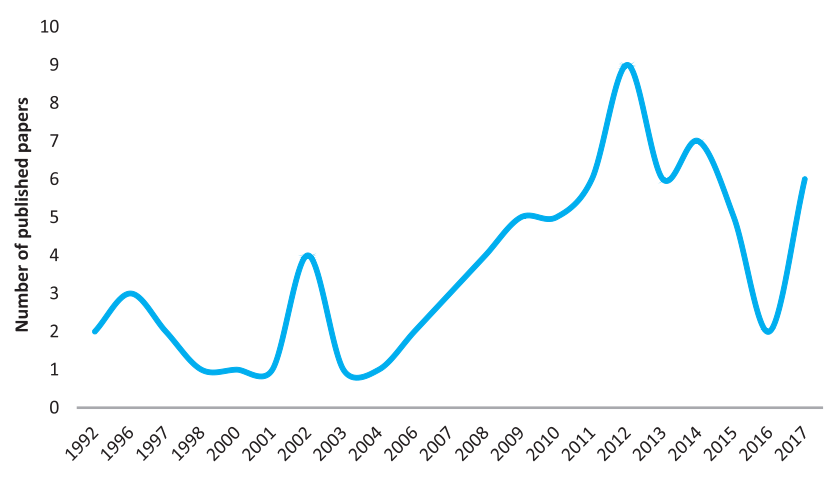

Figure 1. Publications per year about frugivory and bird-plant interactions in Brazil from 1992 to 2017.

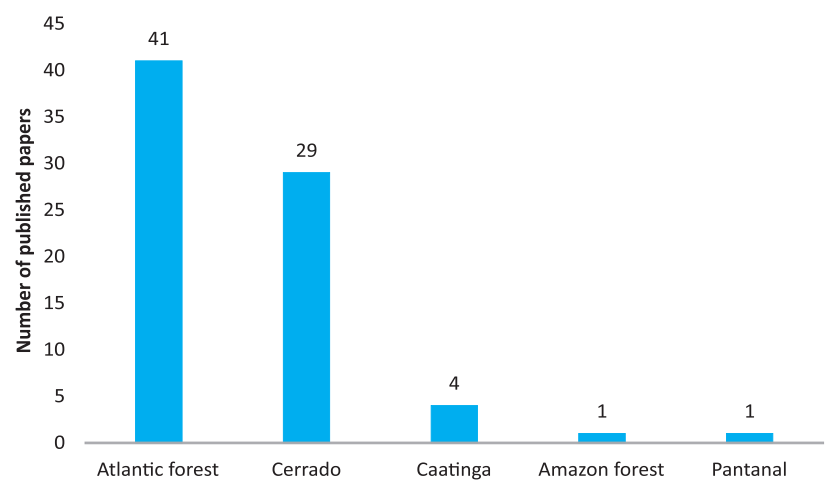

Figure 2. Number of publications about bird-plant interactions and frugivory in Brazilian biomes from 1992 to 2007.

birds were found interacting in Brazil, with the Atlantic Forest being the biome with the most records of species $(80.2 \%$ of plants and $72.9 \%$ of birds of the total of species registered for the biome), followed by the Cerrado ( $21 \%$ of plants and $60 \%$ of birds of the total of species registered for the biome).

The metrics of the constructed complex ecological network of the species recorded for the Atlantic Forest of Brazil (393 plants and 186 birds) revealed that the strongest interaction (degree of connection: 6) occurred between Euterpe edulis (Arecaceae) and Turdus albicollis (Turdidae). This interaction was followed by interactions between Schinus terebinthifolius (Anacardiaceae) and Tangara sayaca (Thraupidae); Guapira opposita (Nyctaginaceae) and T. albicollis; and E. edulis with Ramphastos vitellinus (Ramphastidae) (degree of connection: 4).

Analysis of centrality revealed that Manacus manacus (Pipridae), and Turdus rufiventris (Turdidae), were the most important species in the network. The closeness degree indicated that Miconia cinannomifolia (Melastomataceae), and T. rufiventris were closer to the other species of the network, while betweenness degree indicated that M. manacus and Penelope superciliaris (Cracidae) were the main intermediary species between two of the networks (Table 5). Finally, the modulatory used generated 10 highly connected groups in the same network $(\mathrm{Q}=0.389)$, with all agglomerates being connected, except for two species that were isolated from the others - Paspalum notatum (Poaceae), and Sporophila nigricollis (Traupidae) - however, this interaction could
Table 4. Number of papers published about bird-plant interactions and frugivory per Brazilian state from 1992 to 2017.

\begin{tabular}{|c|c|c|}
\hline Brazilian State & $\mathbf{N}$ & $\%$ \\
\hline São Paulo & 32 & 41.6 \\
\hline Minas Gerais & 13 & 16.9 \\
\hline Rio de Janeiro & 6 & 7.8 \\
\hline Rio Grande do Sul & 6 & 7.8 \\
\hline Santa Catarina & 4 & 5.2 \\
\hline Goiás & 3 & 3.9 \\
\hline Mato Grosso & 3 & 3.9 \\
\hline Ceará & 2 & 2.6 \\
\hline Mato Grosso do Sul & 2 & 2.6 \\
\hline Paraíba & 2 & 2.6 \\
\hline Alagoas & 1 & 1.3 \\
\hline Bahia & 1 & 1.3 \\
\hline Espírito Santo & 1 & 1.3 \\
\hline Pará & 1 & 1.3 \\
\hline Total & 77 & 100.0 \\
\hline
\end{tabular}

Table 5. Species of plants and birds with the highest values of centrality metrics in the biomes analyzed. CeD: Centrality degree, CID: Closeness degree, BD: Betweenness degree.

\begin{tabular}{llllll}
\hline \multicolumn{1}{c}{ Biome } & Group & \multicolumn{1}{c}{ Species } & CeD & CID & BD \\
\hline Atlantic forest & Bird & Manacus manacus & 77 & 0.39 & 0.14 \\
Atlantic forest & Bird & Turdus rufiventris & 67 & 0.40 & 0.07 \\
Atlantic forest & Bird & Penelope superiliaris & 42 & 0.35 & 0.08 \\
Atlantic forest & Plant & Myrsine coriacea & 43 & 0.37 & 0.04 \\
Atlantic forest & Plant & Miconia cinannomifolia & 42 & 0.42 & 0.07 \\
Atlantic forest & Plant & Guapira opposita & 24 & 0.39 & 0.02 \\
Cerrado & Bird & Turdusleucomelas & 35 & 0.44 & 0.13 \\
Cerrado & Bird & Tangara cayana & 27 & 0.41 & 0.08 \\
Cerrado & Bird & Rhamphastos toco & 23 & 0.36 & 0.12 \\
Cerrado & Plant & Miconia albicans & 41 & 0.42 & 0.14 \\
Cerrado & Plant & Cecropia pachystachya & 32 & 0.41 & 0.11 \\
Cerrado & Plant & Schefflera morototoni & 29 & 0.38 & 0.14 \\
\hline
\end{tabular}

be considered as seed predation since that plant species does not produce edible fleshy fruits (Fig. 3).

In the Cerrado, 103 species of plants interacted with 153 species of birds. The most recorded interaction was between Ramphastos toco (Ramphastidae) and Cecropia pachystachya (Urticaceae) (degree of connection: 4), being followed by Miconia albicans (Melastomataceae) with Volantinia jacarina (Thraupidae), Tangara cayana (Thraupidae) and Pitangus sulphuratus (Tyrannidae) (degree of connection for each: 3). According to degree of centrality, M. albicans is the species with the most interactions recorded in the Cerrado, followed by Turdus leucomelas (Turdidae) and C. pachystachya.

Centrality by closeness indicated that $T$. leucomelas was closer to the other species in the network, followed by M. albicans, T cayana, and C. pachystachya. Miconia albicans was also the most intermediary species in the network, followed by Schefflera morototoni (Araliaceae), $T$. leucomelas and R. toco (Table 5). Lastly, the calculation of modularity indicated eight agglomerates with $\mathrm{Q}=0.395324$, which were all interconnected in a single network (Fig. 4). 


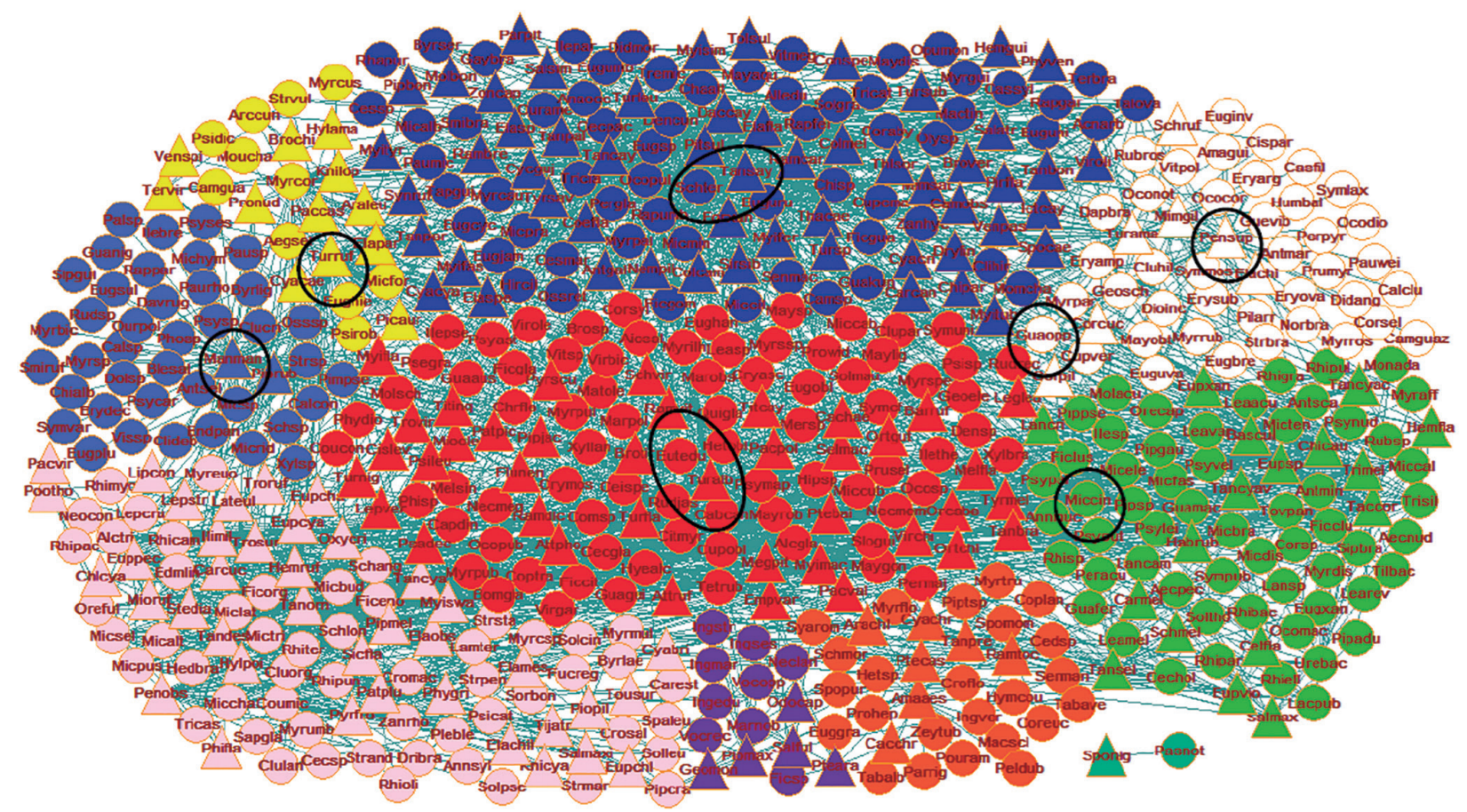

Figure 3. Complex ecological network constructed with information about interactions between frugivorous birds (triangles) and plants (circles) in the Brazilian Atlantic Forest. Each color represents an agglomerate of species that are more connected among themselves than with species of other agglomerates. Species with the highest values of connectivity and centrality are circled. Names in triangles and circles are abbreviations of species names. Abbreviations are defined in the supplementary material (S1).

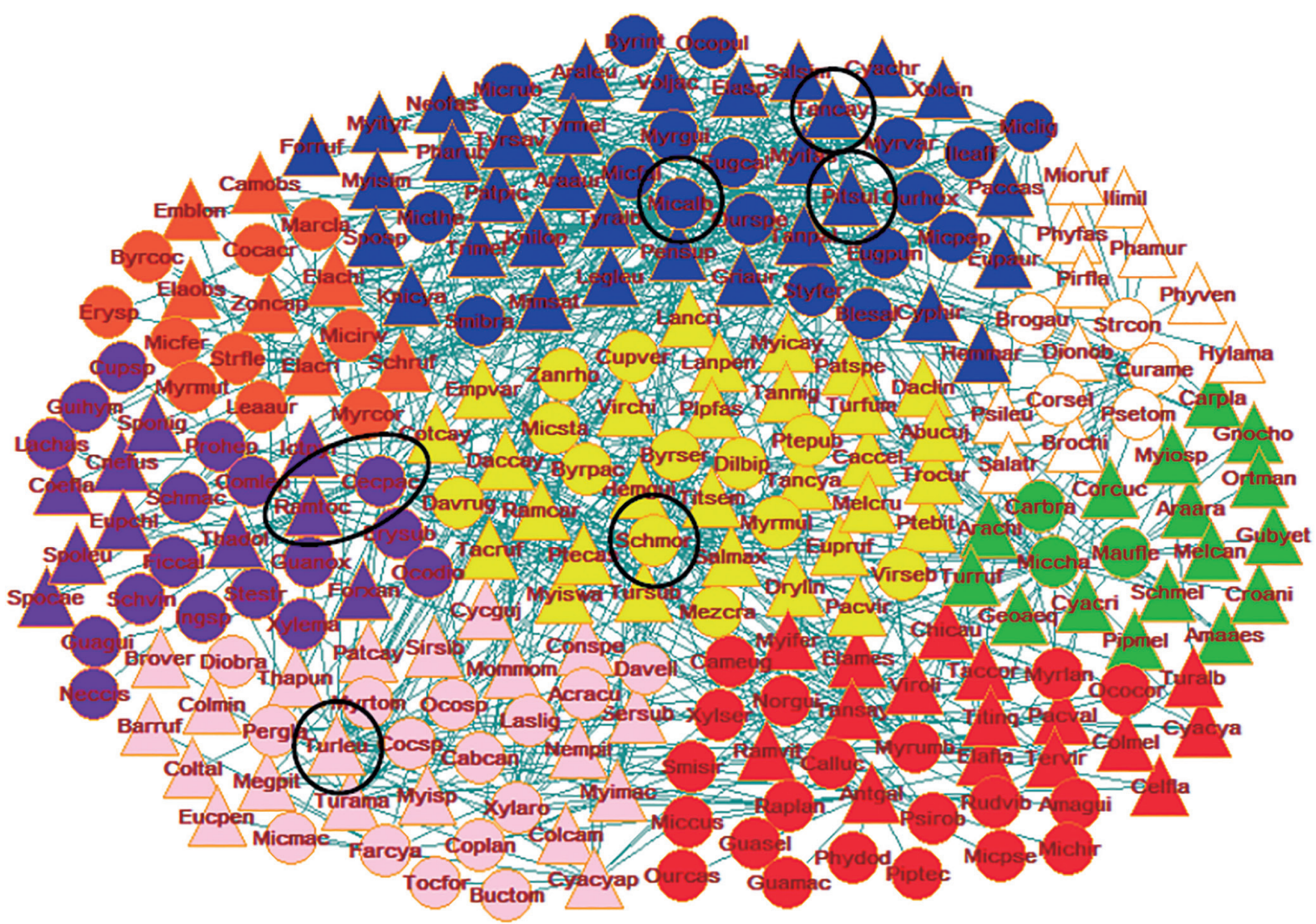

Figure 4. Complex ecological network constructed with information about interactions between frugivorous birds (triangles) and plants (circles) in the Brazilian Cerrado. Each color represents an agglomerate of species that are more connected among themselves than with species of other agglomerates. Species with the highest values of connectivity and centrality are circled. Names in triangles and circles are abbreviations of species names. Abbreviations are defined in the supplementary material (S1). 
In addition to the interactions among native Brazilian species, non-native plant species were also recorded interacting with frugivorous birds in the Atlantic Forest (18 species) and in the Cerrado (three species). The interaction with the highest degree of connection in the Atlantic Forest was between Melia azederach (Meliaceae), and T. leucomelas (3). The species with the highest degree of centrality, by proximity and intermediate, was $M$. zederach $(21,0.57$, and 0.43 , respectively) with a modularity of $Q=0.55$, with five agglomerates, all of them connected with each other (Fig. 5A).

In the Cerrado, Magnolia champaca (Magnoliaceae) had the greatest relative importance in the network for having a degree of centrality with 19 interactions with birds, followed by Muntingia calabura (Mutingiaceae) (14 interactions). Closeness centrality revealed that $M$. champaca had the greatest proximity $(0.5526)$, followed by Turdus amaurochalinus (Turdidae), T. leucomelas, P. sulphuratus and T. sayaca (0.4859). Magnolia champaca
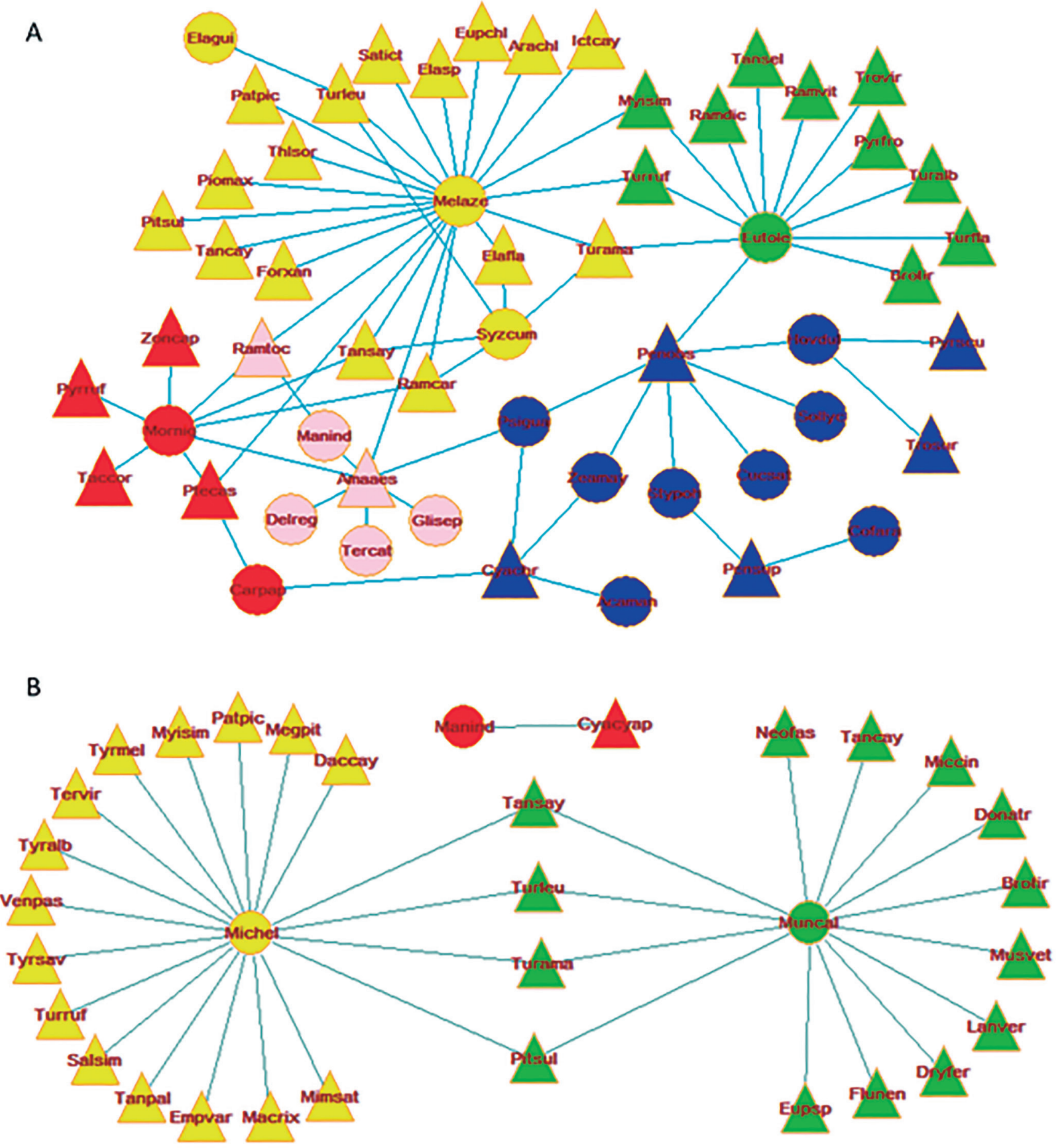

Figure 5. Complex ecological network constructed from information about interactions between frugivorous birds (triangles) and non-native plants (circles) in the Brazilian Atlantic Forest (A) and Cerrado (B). Each color represents an agglomerate of species that are more connected among themselves than with species of other agglomerates. Names in triangles and circles represent are abbreviations of species names. Abbreviations are defined in the supplementary material (S1). 
also had the highest degree of betweenness centrality between any two species in the net (0.6714), followed by $M$. calabura (0.5). Finally, modularity revealed three agglomerates with $Q=0.410035$ (Fig. 5B). Because all of these interactions in the Cerrado were recorded once, but in different publications, there was no sense in calculating connectivity.

\section{DISCUSSION}

The study of frugivory and bird-plant interactions has grown in Brazil over the last few decades, with most of the papers being published in 2011-2017. This finding corroborates those of Pizo \& Galetti (2010), who reported increases in studies on this subject beginning in the year 2000. Angulo (2011) found 39 papers about bird-plant interactions in Brazil up to 2011, and detected an increase in the number of published papers over the years. In the present study, few articles were found about this topic in 2016 , probably due to a lack of financing or interest. On the other hand, almost all the investigations were carried out with national resources and very few with foreign resources, which may be because the majority of researchers do not usually seek external financing or because of the difficulties that exist to learn of and acquire subsidies for this type of research.

Evaluation of the distribution of these studies makes it clear that not all Brazilian biomes or states are equally explored. Most of the publications are for studies conducted in the Atlantic Forest and Cerrado in central-south Brazil. Studies reporting bird-plant interactions in the Amazon Rainforest and the Caatinga are virtually non-existent. However, it is important to note that some papers were excluded from the present analysis because they did not specify the species involved in interactions, and so this finding may be an underestimate.

Bello et al. (2017) identified the São Paulo and Rio de Janeiro as the states with the greatest number of researchers in the country (60\% and $8 \%$, respectively), both of the southeastern region of Brazil. Pizo \& Galetti (2010) reported that bird-plant researchers are more common in the Atlantic Forest and Cerrado biomes and very scarce in the Amazonia and the Caatinga biomes, corroborating the findings of the present study. These environments are very species-rich and have their own unique biodiversity; the Amazonia biome hosts one third of the world's species and the Caatinga is a unique biome to Brazil (Costa, 2010). Nonetheless, the greater number of studies in central-south Brazil is likely due to the greater number of people, universities and researchers in the region and its biomes (Cross et al., 2017). In addition, central-south Brazil concentrates a greater amount of money than other regions, which translates to more funding for such research (IBGE \& COPIS, 2018). All of these observations highlight the importance of investing more in research on bird-plant interactions in the other biomes found by the present analysis to have fewer publications. This is especially important since such research will help to determine the best way to preserve the ecosystems of these biomes, which are equally important for the ecological survival of these regions and states.

There were a greater number of frugivorous birds interacting with plants recorded for the Atlantic Forest than for the Cerrado (186 birds and 393 plants vs. 153 birds and 103 plants, respectively). Bello et al. (2017) reported 232 species of frugivorous birds for the Atlantic Forest from 166 published and unpublished papers. Kuhlmann \& Ribeiro (2016) reported 182 species of frugivorous birds for the Cerrado. Similarly, there are 788 plant species whose fruits are consumed by more than 300 vertebrates in the Atlantic Forest (Bello et al., 2017), and 945 plants with zoochoric dispersion in the Cerrado (Kuhlmann \& Ribeiro, 2016). Thus, the present bibliometric analysis recorded $20.13 \%$ of the birds and $1.03 \%$ of the plants of the Cerrado, and $20.06 \%$ of the birds and $1.9 \%$ of the plants of the Atlantic Forest (Costa, 2010).

Most of plant species with high values for network metrics, like degree of connection and centrality degrees in both the Atlantic Forest and Cerrado, are trees, such as E. edulis, C. pachystachya and S. terebinthifolius, all of which are known to have sweetened fruits, wide distributions and to be recommended for heterogeneous reforestations (Lorenzi, 2002). Regarding the birds, the species with high values for network metrics in both Atlantic Forest and Cerrado, like T. rufiventris, T. albicollis, T. leucomelas and T. cayana, are all widely distributed in Brazil, are tolerant of human presence and are omnivorous (Sigrist, 2014). Besides, the most recorded bird species were those that are easily detected and identified because they are more conspicuous. Due to these characteristics and facilities, the presence of these species is very important for conservation and restoration of ecological services, but according to Mello et al. (2015), these types of species have different degrees of network centrality in different locations.

On the other hand, the low modularity in the networks with native plant species, unlike non-native ones, may be due to the fact that the latter have few records and studies on their interactions with wildlife or also because the diversity of local flora is much higher. Finally, Bello et al. (2017) reported 59 non-native plant species for the Atlantic Forest, this discrepancy is surely a result of the present analysis only considering reports from accessible published articles, unlike Bello et al. (2017) who considered many other types of sources.

\section{CONCLUSION}

Gap analysis revealed that: (1) the states and universities in the North and Northeast regions of Brazil produced few or no studies on frugivory and seed dispersal by bird-plant networks; (2) there is a pattern of increasing publications of studies on seed dispersal by frugivorous birds in Brazil; (3) Brazilian biomes, like the Pampas, Amazon Rainforest, Caatinga and Pantanal are being neglected; and (4) there are keystone plant and bird species in the Atlantic Forest and Cerrado that should be considered for regeneration studies. 


\section{ACKNOWLEDGEMENTS}

The authors would like to thank Federal University of Ouro Preto and CAPES for supporting the research and OEA/GCUB for the scholarship to CDVB. The authors also thank $A A B C$ for data collection and RJY for English revision and suggestions to the first draft of this paper. Finally, the authors would like to thank the anonymous referees for their invaluable suggestions to improve the quality of this paper.

\section{REFERENCES}

Allenspach, N. \& Dias, M. 2012. Frugivory of birds on Miconia albicans (Melastomataceae) in a fragment of cerrado in Sao Carlos, southeastern Brazil. Brazilian Journal of Biology, 72(2): 407-413.

Angulo, A. 2011. Dispersión de semillas por aves frugivoras: Una revisión de estudios de la región neotropical. (Proyecto de tesis para título de licenciatura en Biología). Universidad Pontificia Javeriana. Bogotá, Colombia.

Azevedo, C.; Cipreste, C. \& Young, R. 2006. Environmental enrichment: a GAP analysis. Applied Animal Behaviour Science, 102: 329-343.

Bello, C.; Galetti, M.; Montan, D.; Pizo, M.; Maringuela, T.; Culot, L.; Bufalo, F.; Labecca, F.; Pedrosa, F.; Constantini, R.; Emer, C.; Silva, W.; Da Silva, F.; Ovaskainen, 0. \& Jordano, P. 2017. Atlantic frugivory: a plant-frugivore interaction data set for the Atlantic Forest. Ecology, 98(6): 1729-1729.

Cardoso da Silva, J.; Uhl, C. \& Murray, G. 1996. Plant succession, landscape management, and the ecology of frugivorous birds in abandoned Amazonian pastures. Conservation Biology, 10: 491-503.

Costa, J.P.0. 2010. Sítios del patrimônio mundial natural de Brasil. Apuntes: Revista de estúdios de patrimônio cultural, 22(2): 184-197. Available at: https://dialnet.unirioja.es/servlet/articulo?codigo $=3661300$.

Cross, D.; Thomson, S. \& Sinclair, A. 2017. Research in Brazil: A report for CAPES by Clarivate Analytics. Brasilia, Clarivate Analytics.

Ferreira, R. \& De Marco, P. 2004, Interações entre aves frugivoras e plantas em um fragmento de mata atlântica de Minas Gerais. Ararajuba, 12(2): 97-103.
Howe, H. \& Smallwood, J. 1982. Ecology of seed dispersal. Annual Review of Ecology and Systematics, 13(1): 201-228.

Instituto Brasileiro de Geografia e Estatística (IBGE) \& Coordenação de População e Indicadores Sociais (COPIS). 2018. Síntese de indicadores sociais: Uma análise das condições de vida da população e indicadores sociais. Rio de Janeiro, Instituto Brasileiro de Geografia e Estatística.

Jordano, P.; Galetti, M.; Pizo, M. \& Silva, W. 2006. Ligando frugivoria e dispersão de sementes à biologia da conservação. In: Duarte C.; Bergallo, H.; Santos, M. \& Sluys, M. Biologia da conservação: Essencias. São Paulo, Ríma. p. 411-436.

Kuhlmann, M. \& Ribeiro, J.F. 2016. Fruits and frugivores of the brazilian Cerrado: ecological and phylogenetic considerations. Acta Botanica Brasilica, 30(3): 495-507.

Levine, J. \& Murrell, D. 2003. The community level consequences of seed dispersal patterns. Annual Review of Ecology, Evolution and Systematics, 34: 549-574.

Lorenzi, H. 2002. Árvores brasileiras: Manual de identificação e cultivo de plantas arbóreas do Brasil. 4.ed. Nova Odessa, Editora Plantarum. 2v.

Mello, M.A.R.; Muylaert, R.L.; Pinheiro, R.B.P. \& Ferreira, G.M.F. 2016. Guia para análise de redes ecológicas. Avaliable at: $h$ ttps://www.researchgate. net/profile/Marco Mello/publication/307940803 Guia para analise de redes ecologicas/links/5ceb0c31458515712ec5f040/Guiapara-analise-de-redes-ecologicas.pdf. Access in: 11/10/2018.

Mello, M.; Rodrigues, F.; Costa, L.; Kissling, W.; Sekercioğlu, C.; Marquitti, F. \& Kalko, E. 2015. Keystone species in seed dispersal networks are mainly determined by dietary specialization. Oikos, 124: 1031-1039.

Pizo, M. \& Galetti, M. 2010. Métodos e perspectivas do estudo da frugivoria e dispersão de sementes por aves. In: Von Matter, S.; Straube, F.; Piacentini, V.; Accordi, I. \& Candido, J. Ornitologia e conservação: Ciencia aplicada, técnicas de pesquisa e levantamento. Rio de Janeiro, Technical Books. p. 492-504.

Ragusa-Netto, J. 2006. Abundance and frugivory of the toco toucan (Rhampastos toco) in a gallery forest in Brazil's southern Pantanal. Brazilian Journal of Biology, 66(1A): 133-142.

Sigrist, T. 2014. Guia de campo avis brasilis: avifauna brasileira. Sao Paulo, Avis Brasilis. 